\title{
Metabolic Network Representation in SBGN PD: EC and Identity Gate
}

\section{Alexander Mazein}

\author{
School of Informatics \\ Centre for Systems Biology at Edinburgh \\ Division of Pathway Medicine
}

University of Edinburgh 
- Proposed new shape for simple chemical - Proposed new entity: functional gate (EC) - Proposed new entity: identity gate 


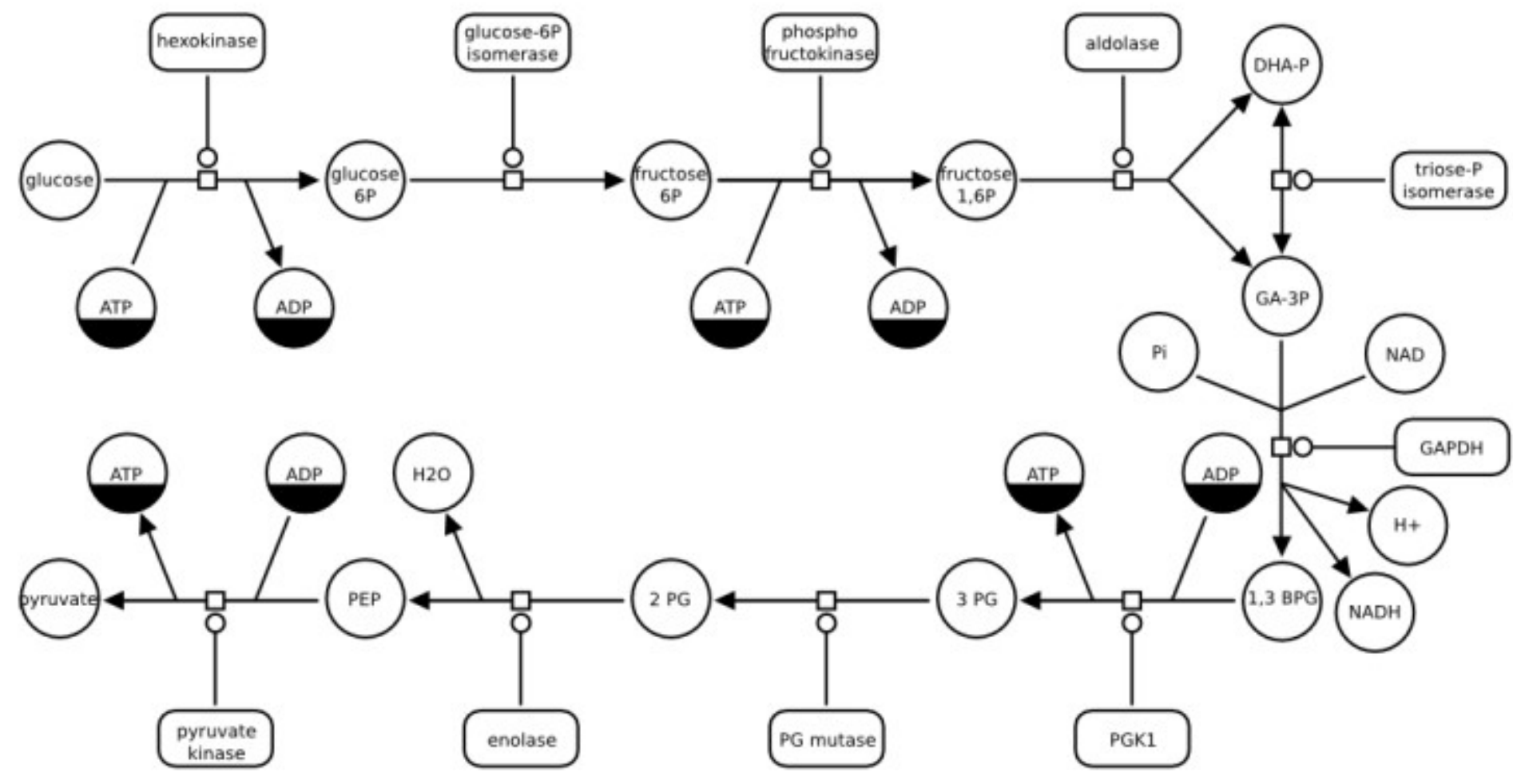

Compound name inside shape 


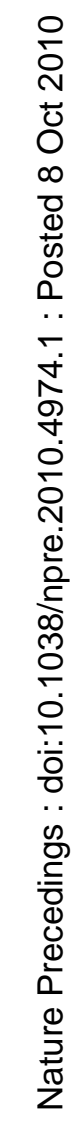
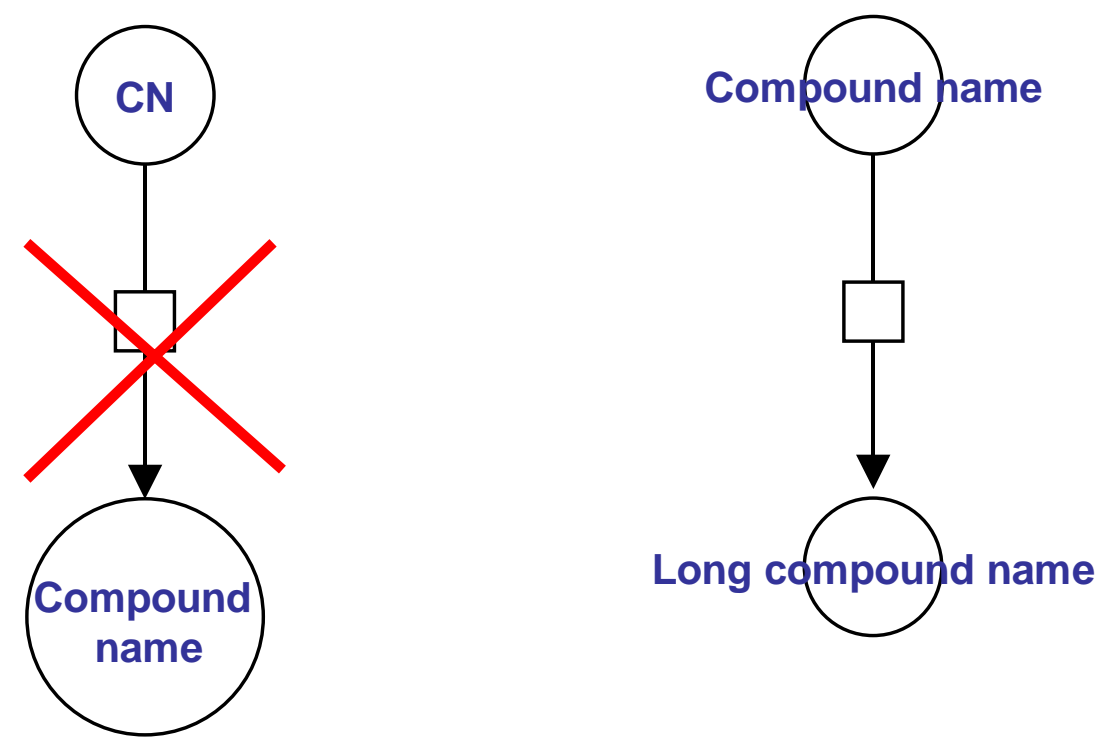


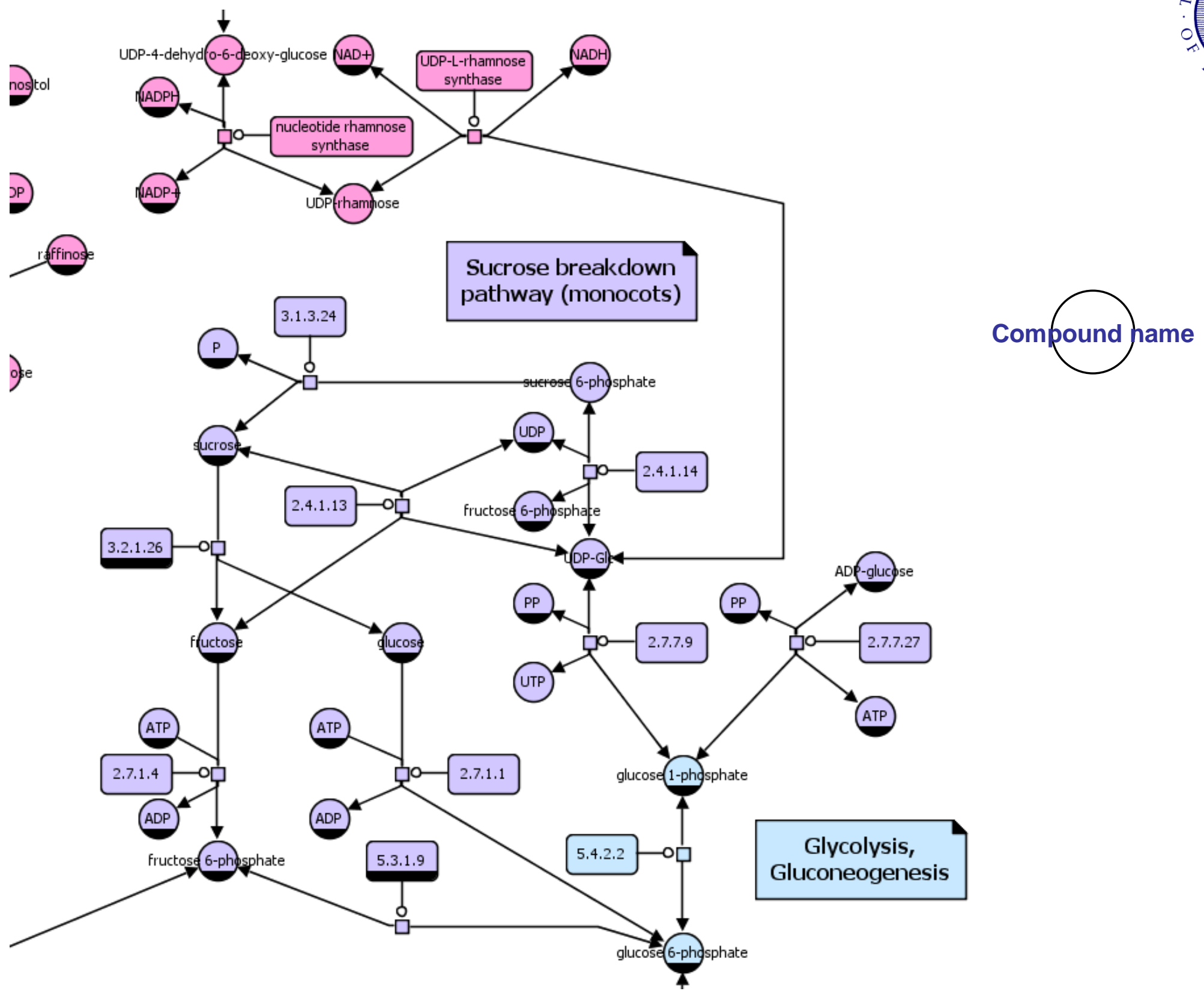




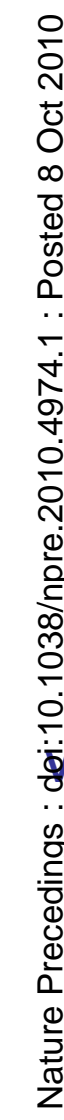
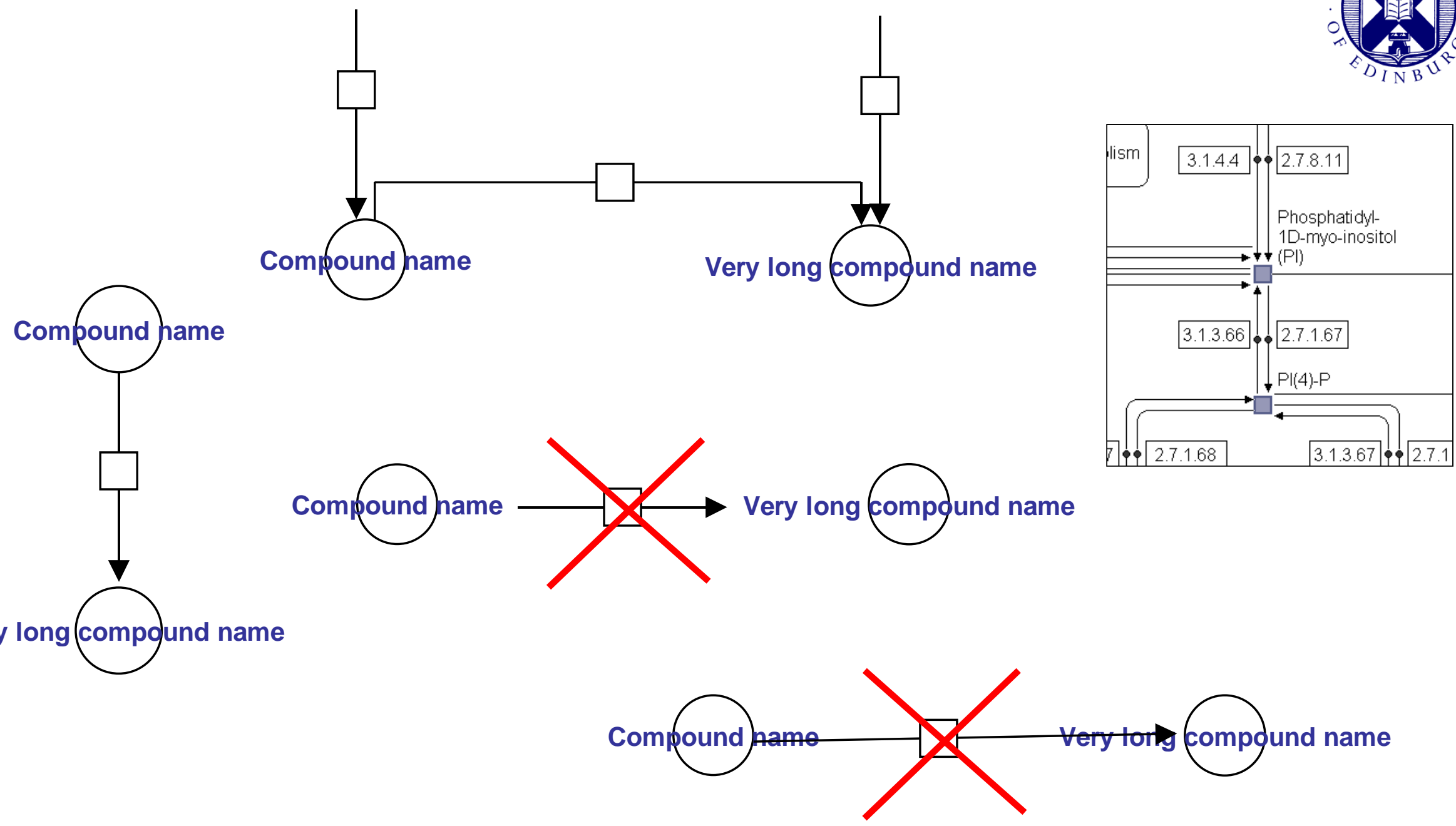

Additional work is required in order to prepare abbreviation for each compound

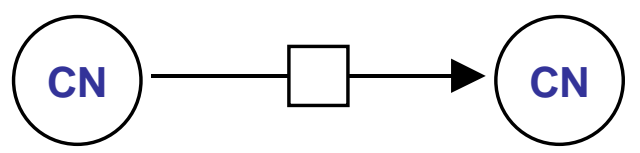

It is going to be more difficult to read maps with abbreviations instead of common compound names 


\section{Proposed new shape for simple chemical entity}

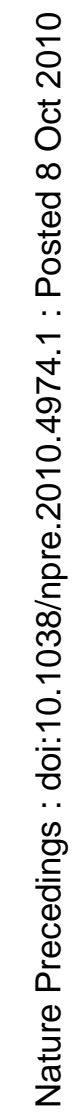

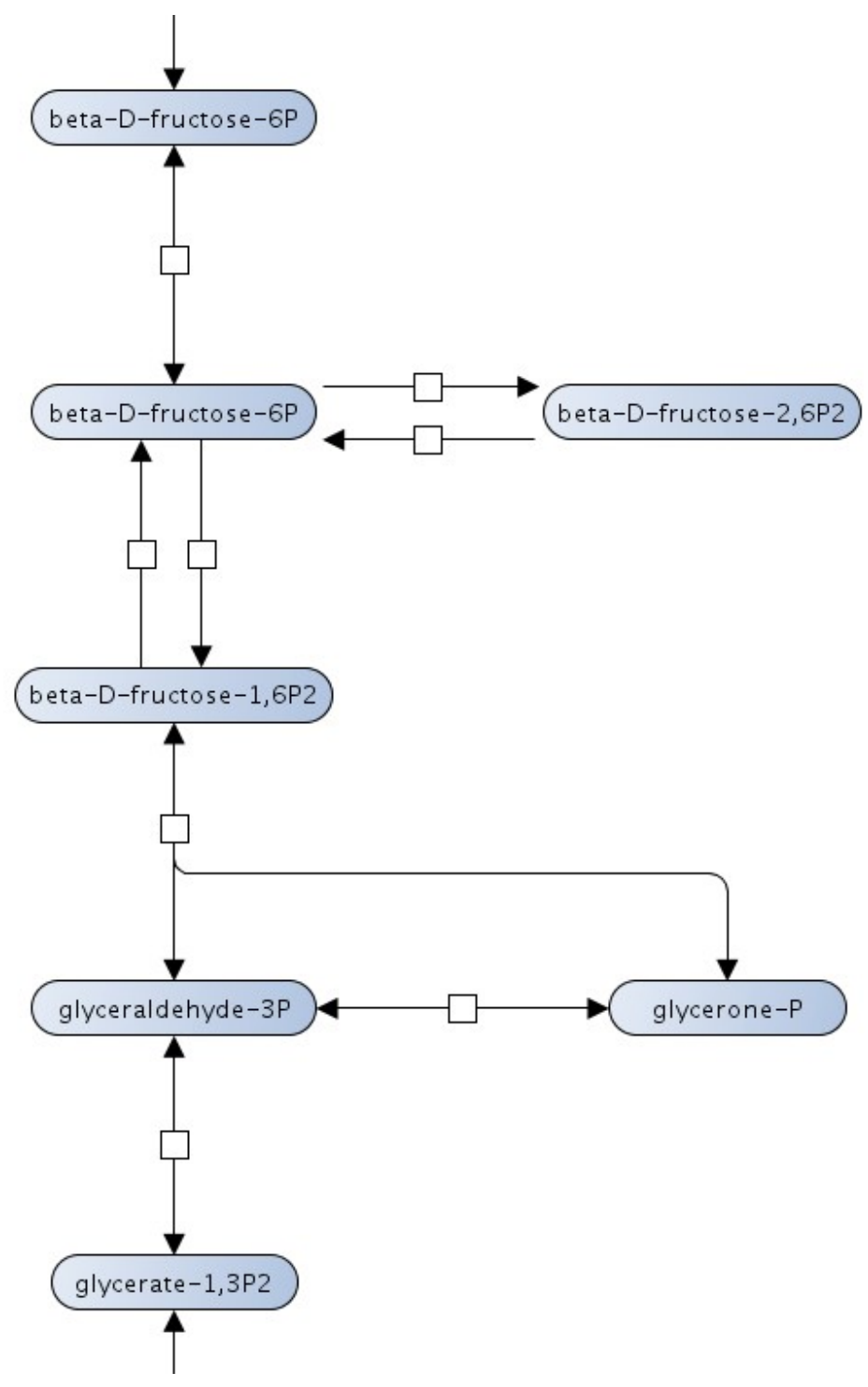




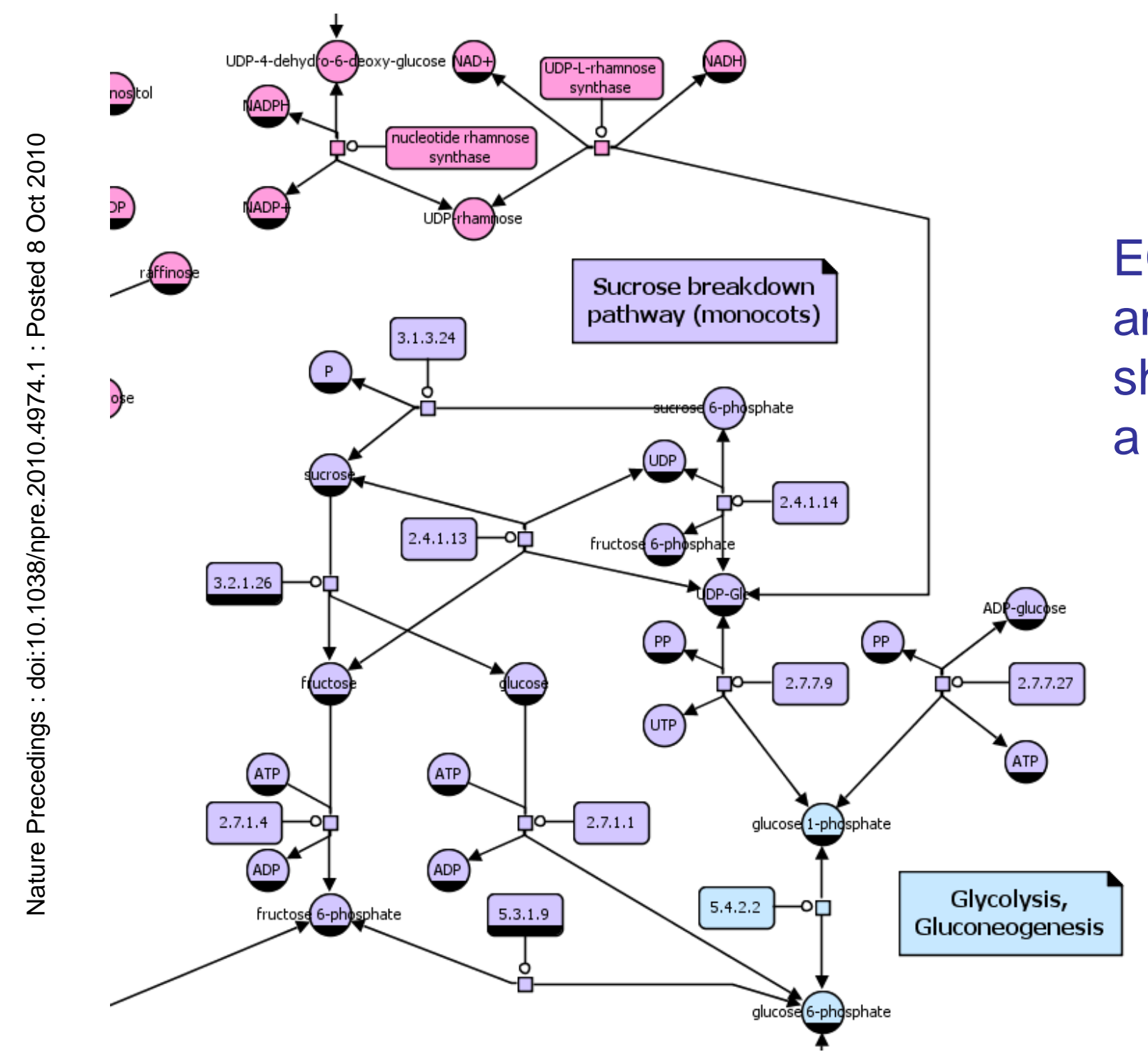

EC is the most compact and informative way to show protein function on a metabolic diagram 

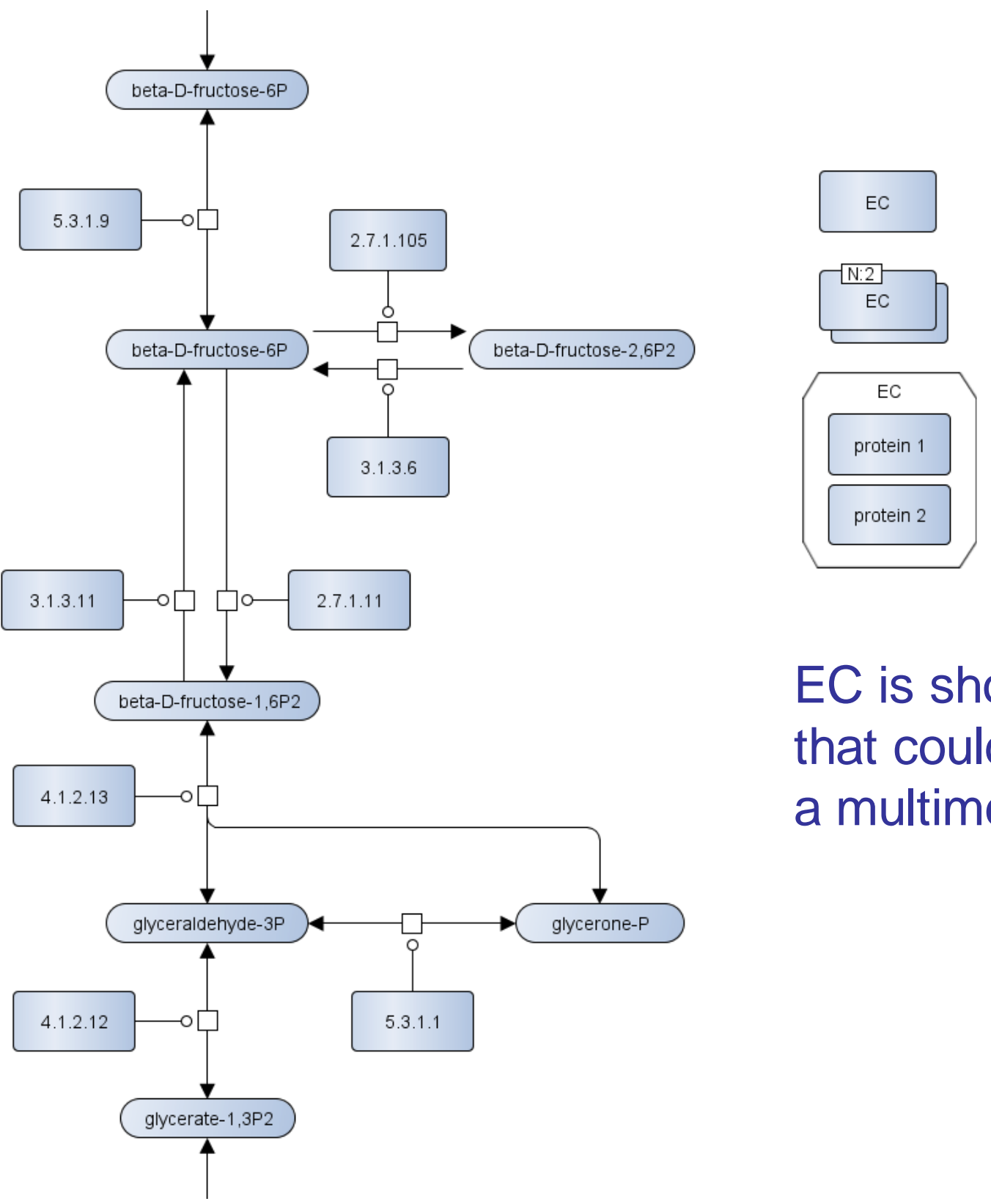

EC is shown as a generic protein, that could symbolize a protein, or a multimer, or a complex 


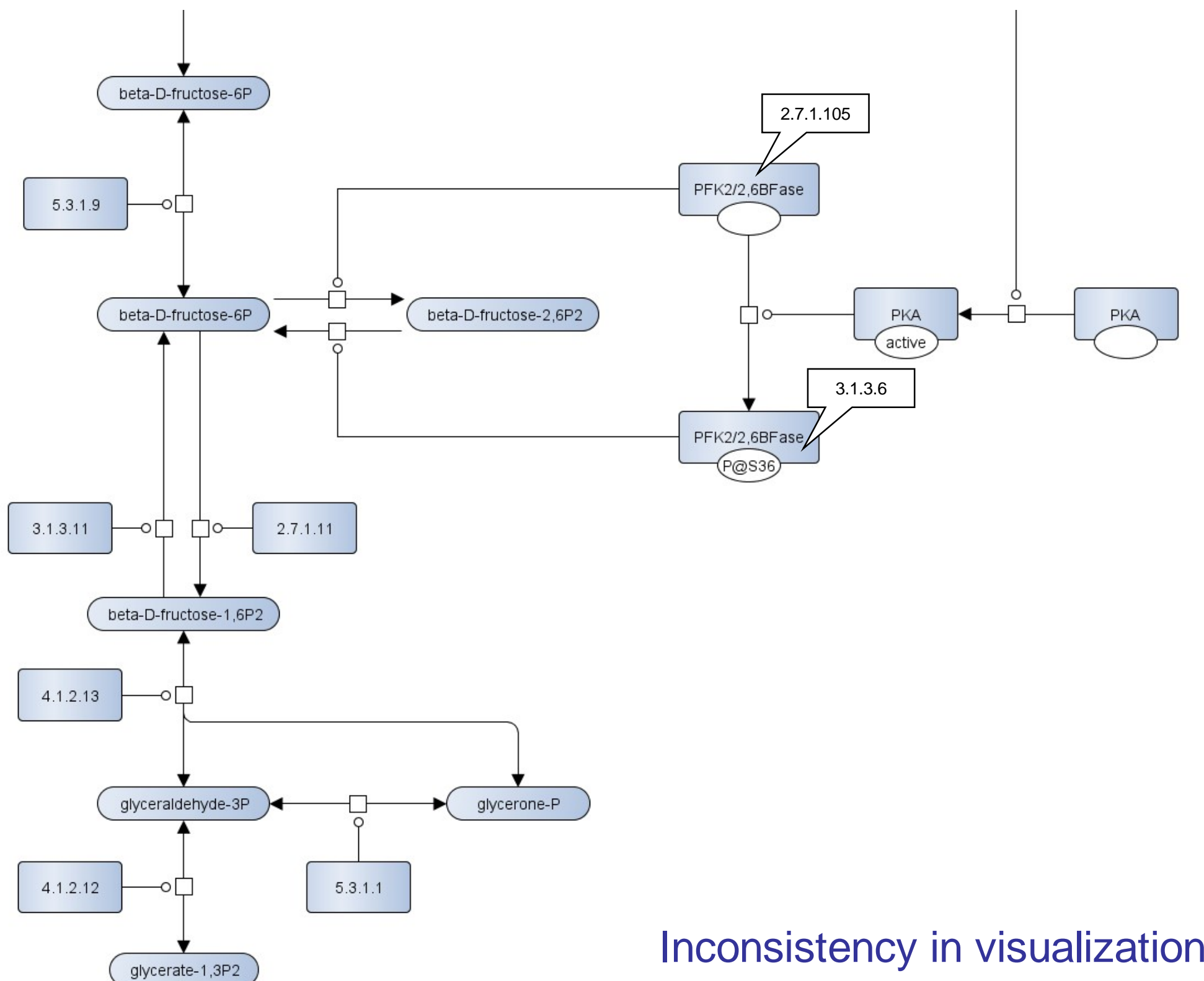




\section{Proposed new entity: functional gate}

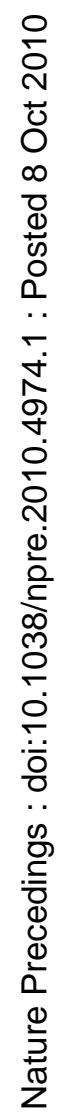

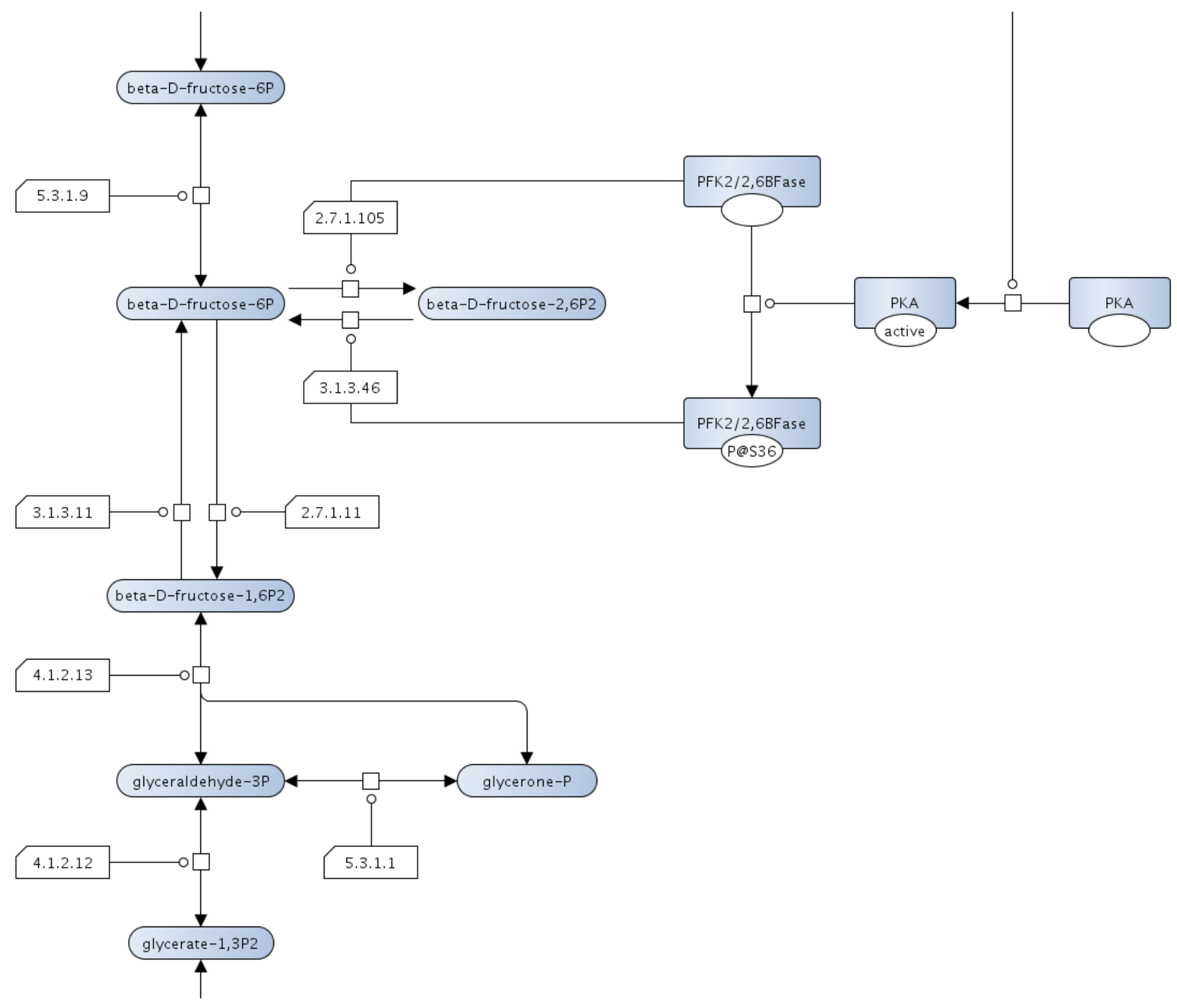




\section{Using identity gate instead of functional gate}

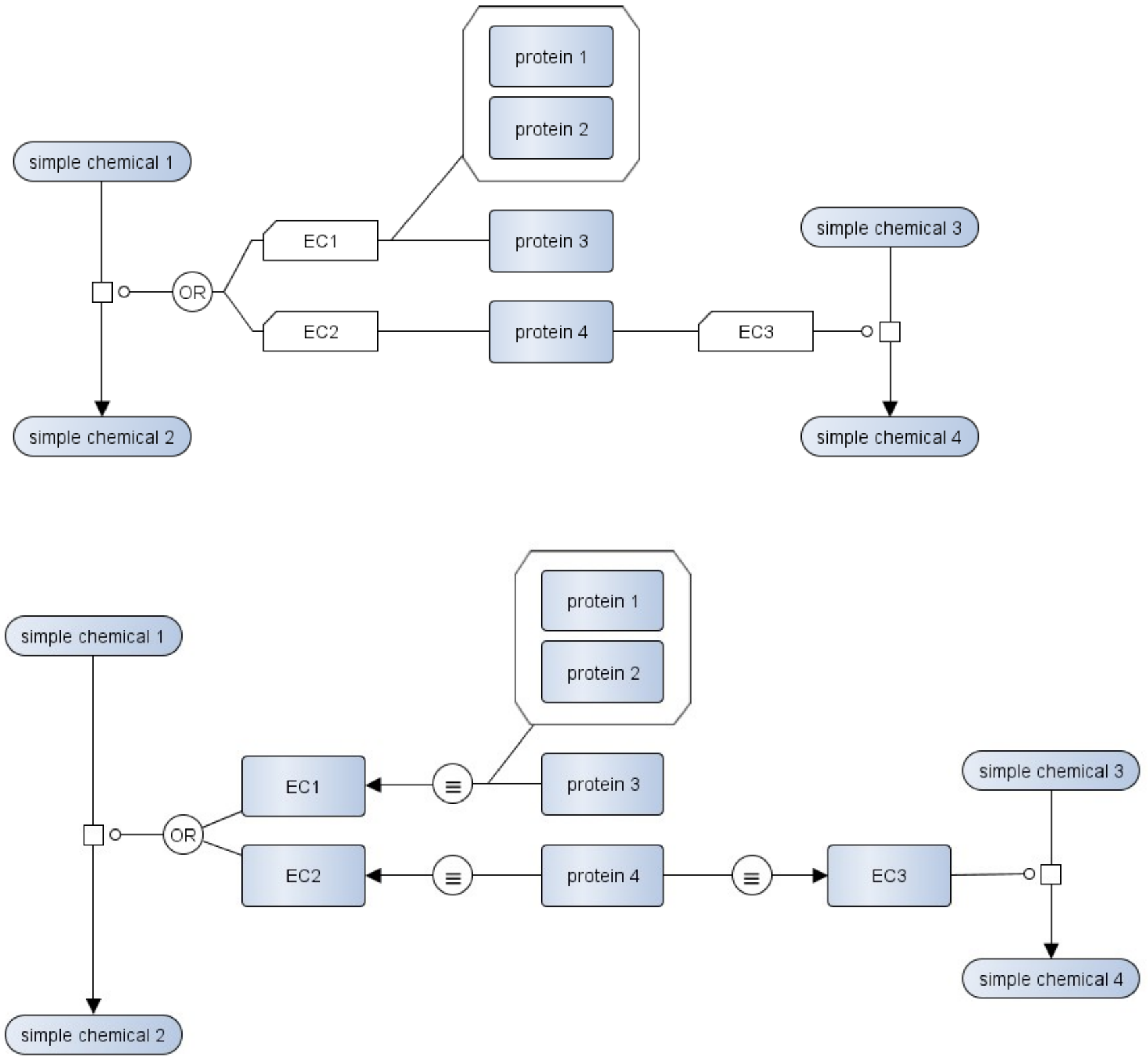




\section{Identity gate}

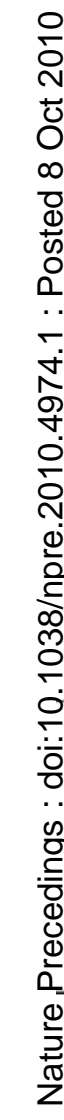
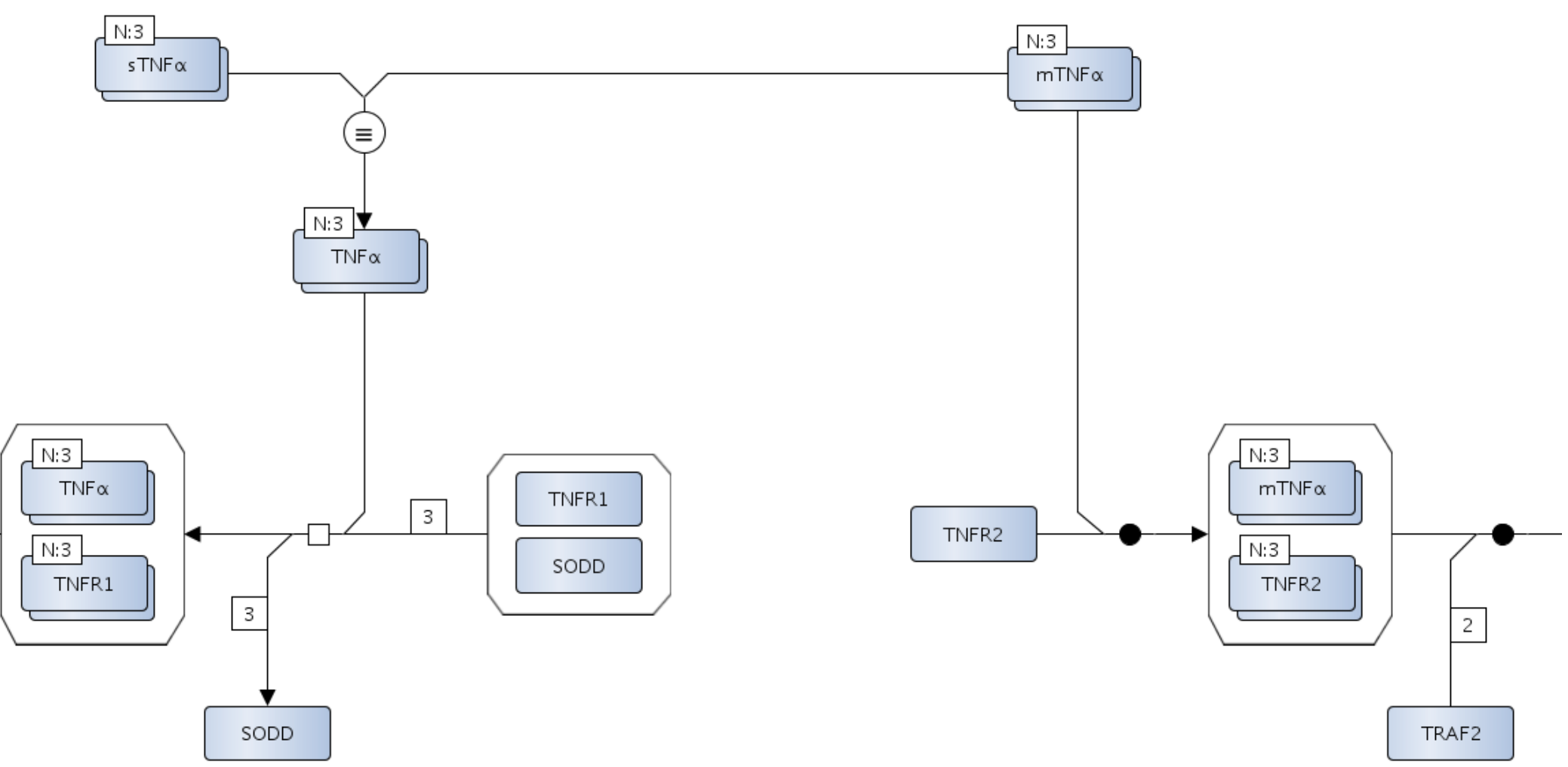


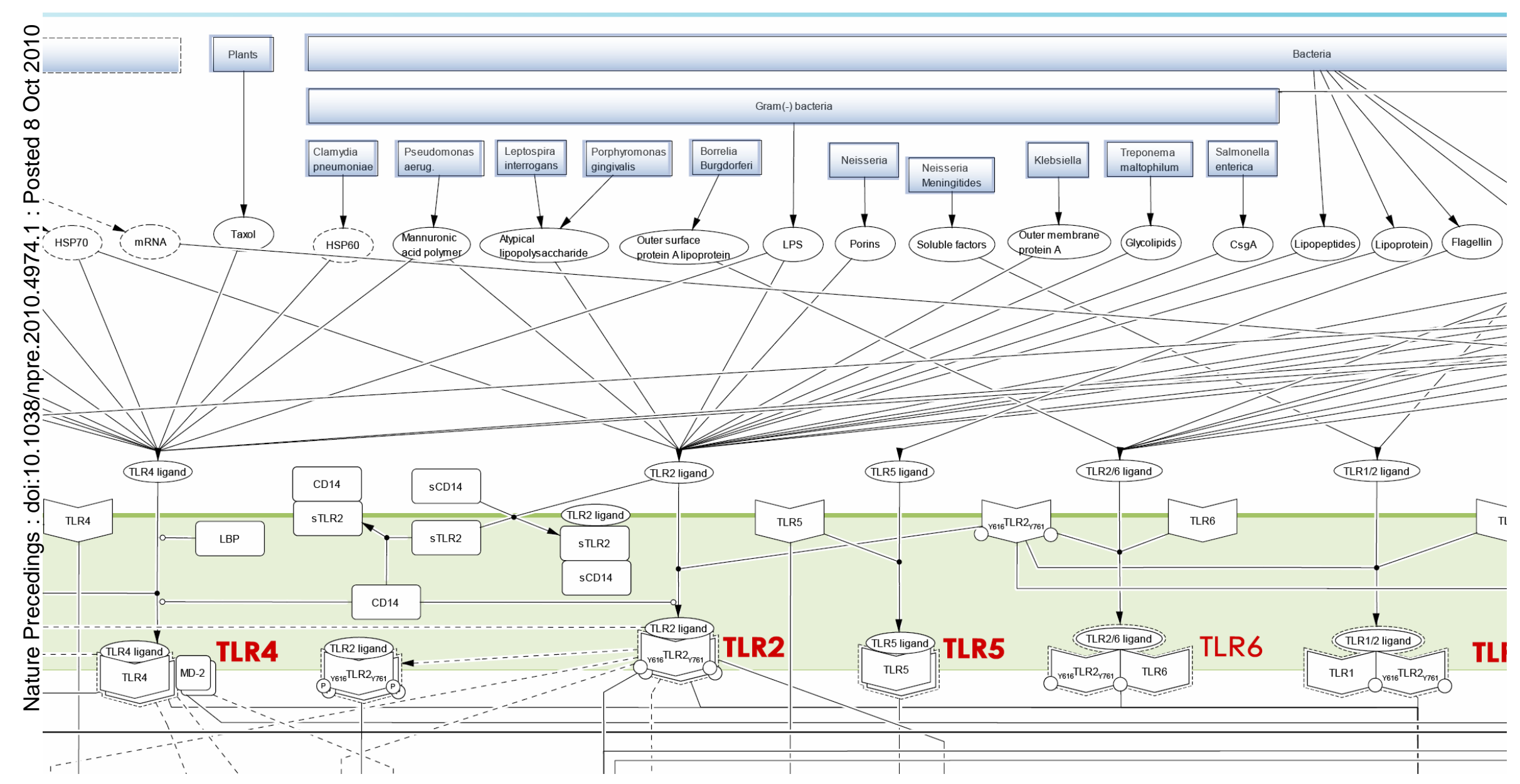




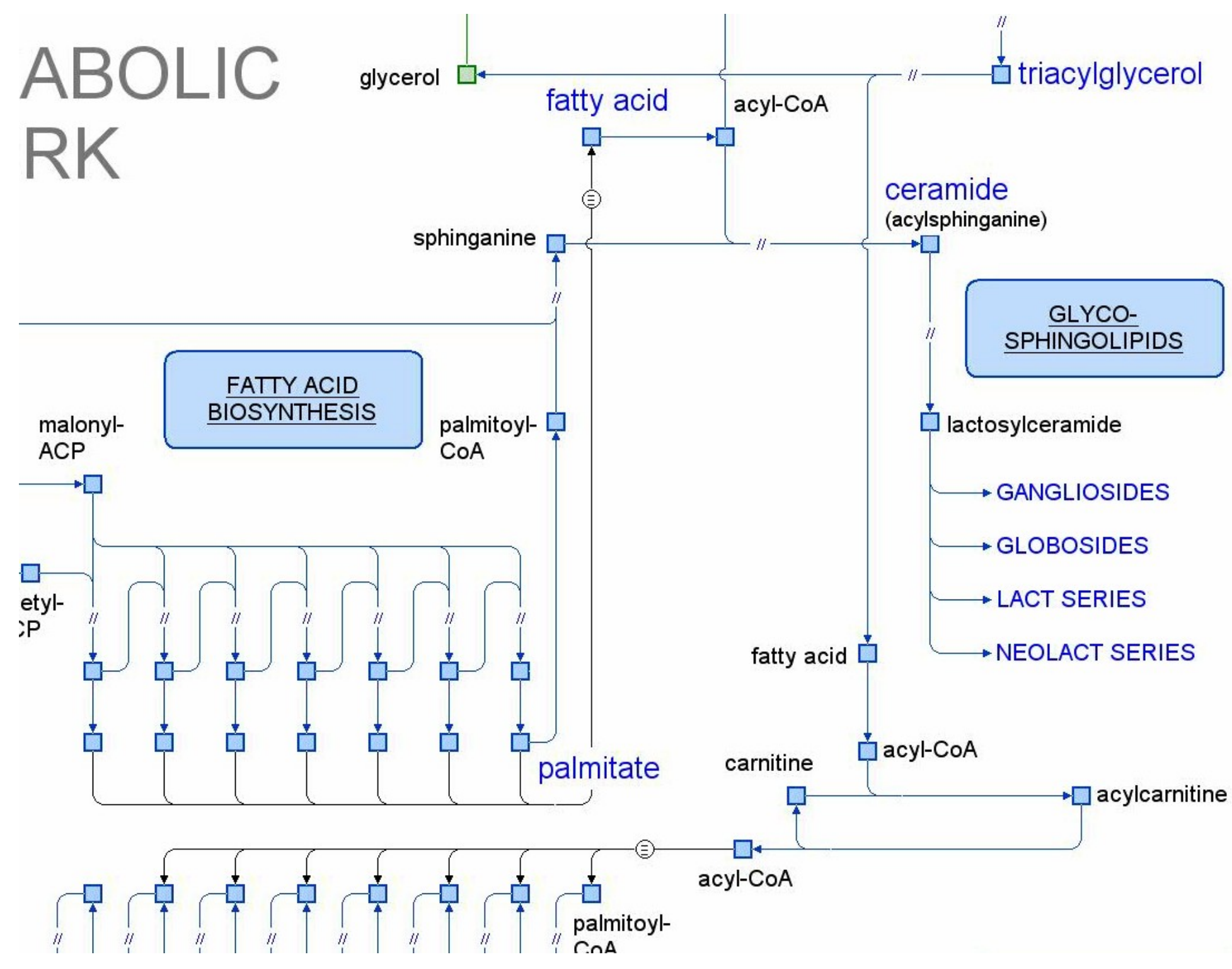




\section{Potentially using identity gates} might cause ambiguity
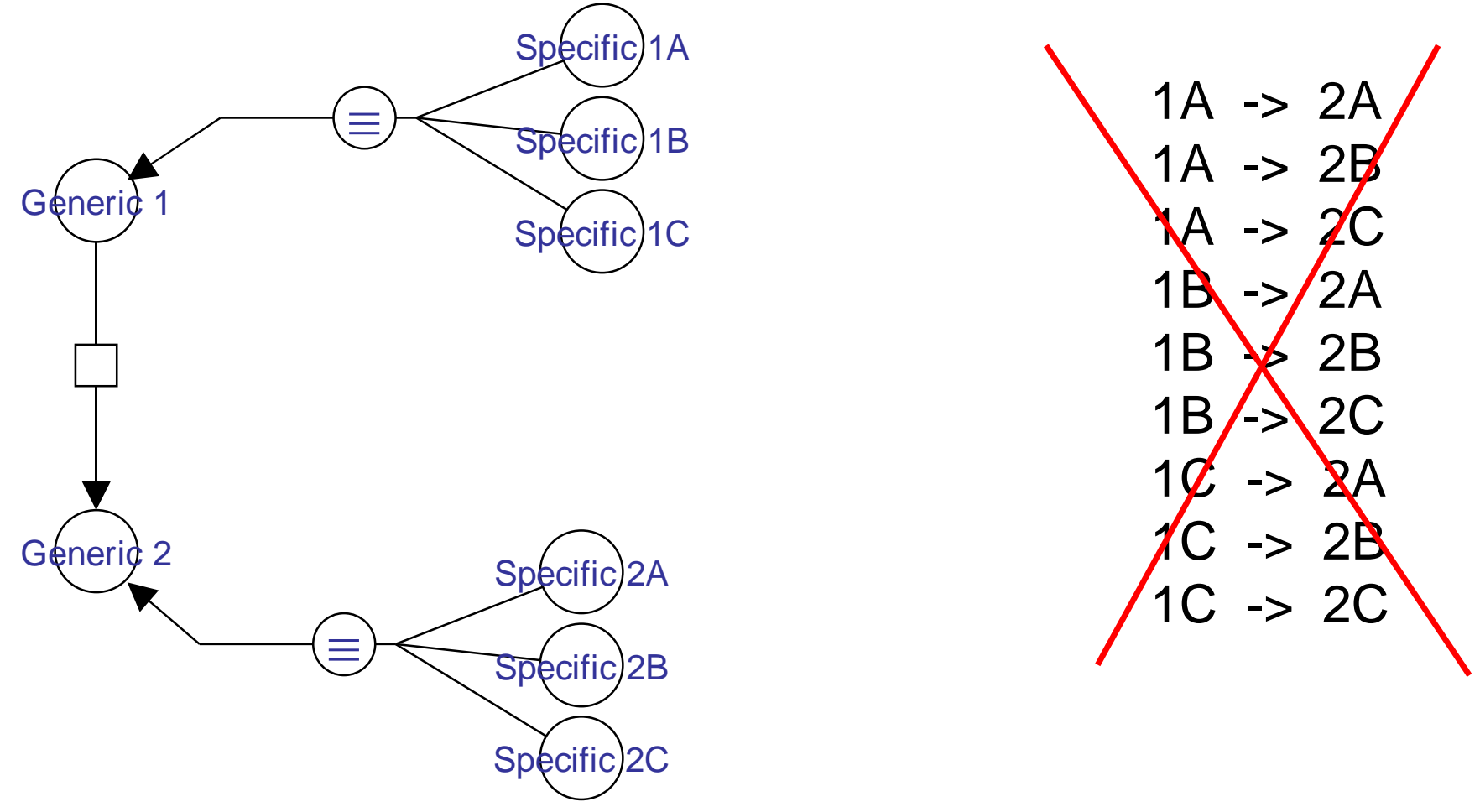

$1 \mathrm{~A} \rightarrow 2 \mathrm{~A}$

$1 \mathrm{~B} \rightarrow 2 \mathrm{~B}$

$1 \mathrm{C} \rightarrow 2 \mathrm{C}$ 


\section{Possible solution: introducing restrictions}

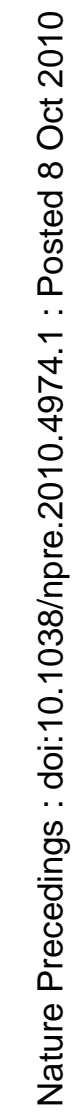

Only 1 identity gate on a map

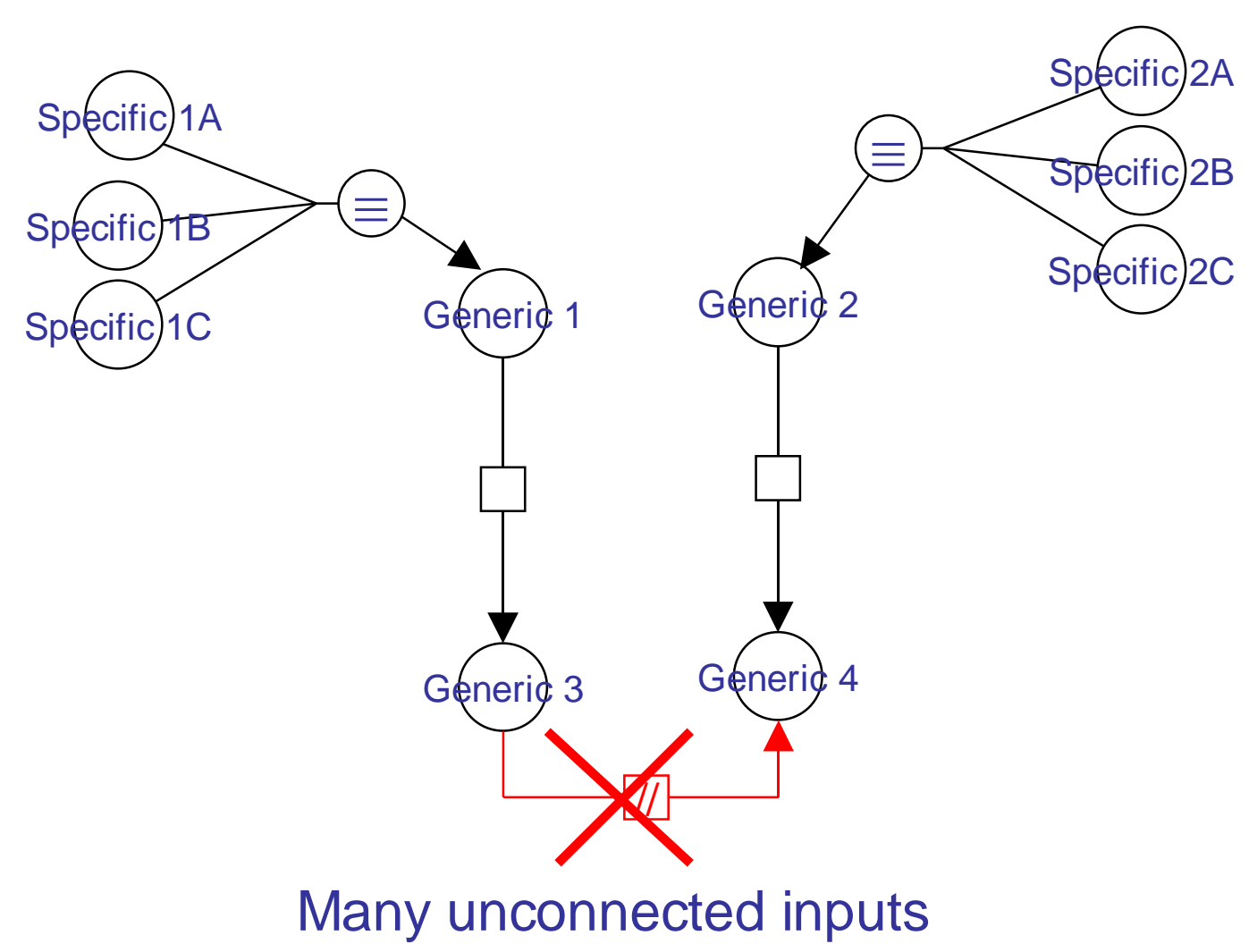




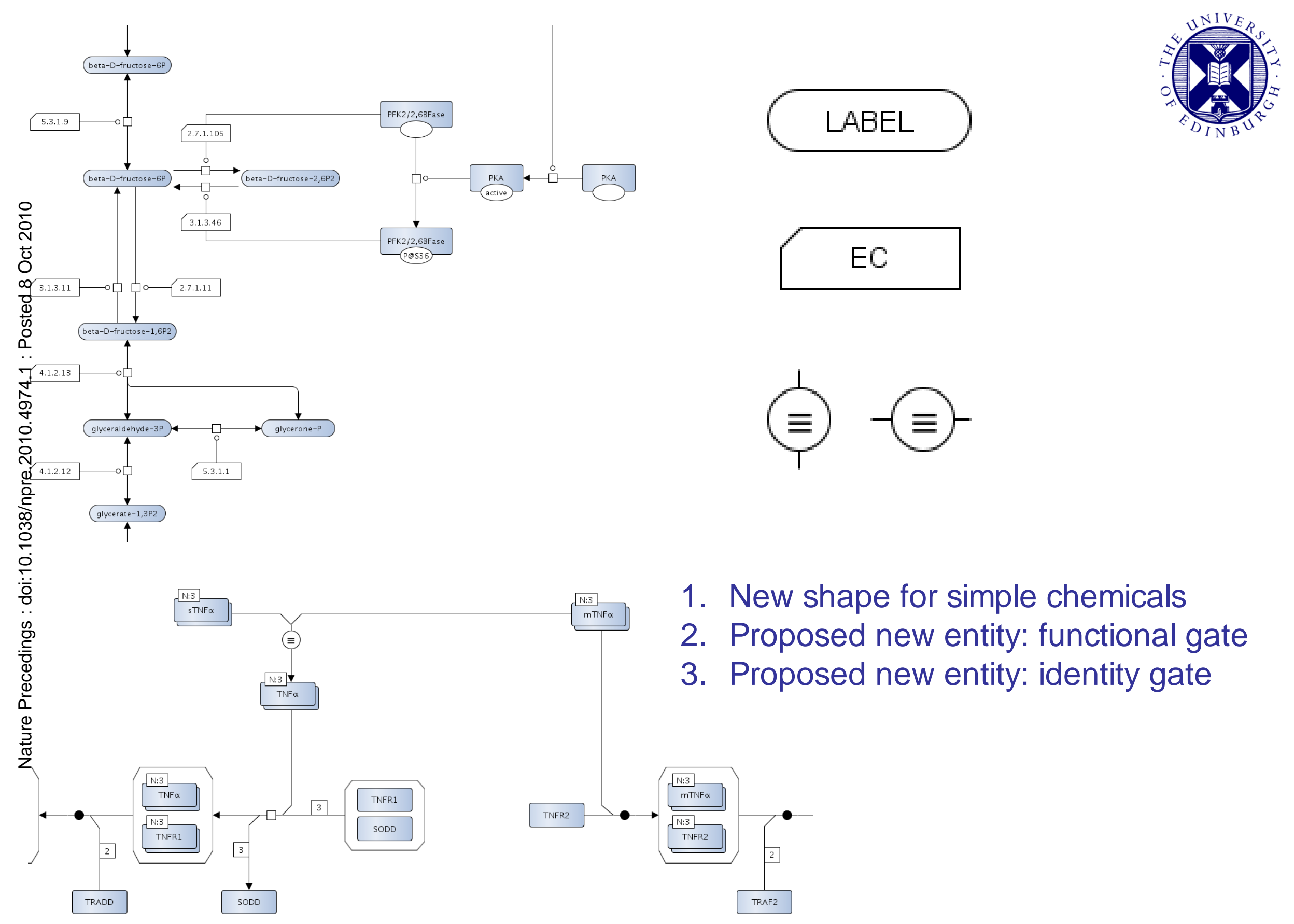




\title{
Acknowledgments
}

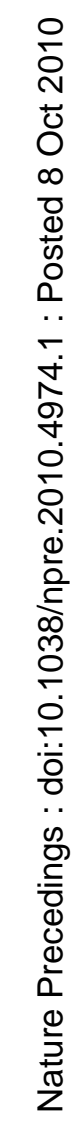

\author{
Stuart Moodie
}

Anatoly Sorokin

Igor Goryanin 


\section{Thank you}

